\title{
Chinese Herbal Medicine-induced Liver Injury
}

\author{
Xin $\mathrm{Ma}^{1}$, Jing-Hua Peng*1,2 and Yi-Yang $\mathrm{Hu}^{1,2,3,4}$ \\ ${ }^{1}$ Institute of Liver Diseases, Shuguang Hospital affiliated to Shanghai University of Traditional Chinese Medicine, Shanghai, \\ China; ${ }^{2}$ Key Laboratory of Liver and Kidney Diseases, Shanghai University of Traditional Chinese Medicine, Ministry of Education, \\ Shanghai, China; ${ }^{3}$ E-institute of Shanghai Municipal Education Committee, Shanghai University of Traditional Chinese Medicine, \\ Shanghai, China; ${ }^{4}$ Shanghai Key Laboratory of Traditional Chinese Clinical Medicine, Shanghai, China
}

\begin{abstract}
The widespread use of Chinese herbal medicine ( $\mathrm{CHM}$ ) and the associated adverse reactions has attracted the attention of researchers and physicians. Reports have shown that several types of CHM can cause liver injury, with increasing numbers of cases reported every year. The difficulty in characterizing CHMinduced liver injury stems from clinical manifestations, diagnosis and pathogenesis. The clinical manifestations are varied, but gastrointestinal symptoms are the majority. The Council for International Organizations of Medical Sciences scale is currently the most commonly used method for assessing causality in cases of medicine-induced liver injury with excellent sensitivity, specificity and predictive validity. However, the pathogenesis of CHM-induced liver injury is not well understood. The classic view encompasses a contribution from "toxic metabolites" that either elicit an immune response or directly affect cellular biochemical processes or functions. In addition, poor quality and inappropriate clinical use of CHMs contribute to safety concerns. To ensure the safe use of $\mathrm{CHMs}$ and decrease the number of hepatotoxic cases, clinicians, researchers and pharmaceutical companies should share responsibility by regulating clinical use, strengthening basic toxicology research and establishing a strict quality control system.

(C) 2014 The Second Affiliated Hospital of Chongqing Medical University. Published by XIA \& HE Publishing Ltd. All rights reserved.
\end{abstract}

\section{Introduction}

For thousands of years, herbs have been used to treat disease in China. Based on the prolonged experience and the original treatment principles, traditional Chinese medicines, which include pharmacy components, are being used in clinics today as an alternative and complementary option to modern Western medicine. Many herbal medicines are commonly used to treat the elderly, pregnant women, and children. Nearly 1.5 million people in the United States have tried herbal treatments, with an annual cost as much as $\$ 1.5$

Keywords: Chinese herbal medicine; Liver injury.

Abbreviations: CHM, Chinese herbal medicine; CIOMS, Council for International Organizations of Medical Sciences; DILI, drug-induced liver injury; HILI, herbal drug-induced liver injury.

Received: 27 February 2014; Revised: 13 August 2014; Accepted: 15 August 2014

DOI: $10.14218 /$ JCTH.2014.00009.

* Correspondence to: Jinghua Peng, No. 528 Zhangheng Road, Pudong District, Shanghai 201203, China. Telephone: +86-021-20256526; Fax: +86-02120256521, Email address: pengjinghua2004@163.com billion. ${ }^{1}$ The use of traditional Chinese medicine has been popular in Germany since the 1980 s, and more than $58 \%$ of the German population use herbal remedies, ${ }^{2}$ which are accessible in pharmacies.

Reports involving adverse reactions caused by Chinese herbal medicine (CHM) have gradually emerged. In recent years, clinical cases and laboratory data have shown that $\mathrm{CHMs}$ and their preparations may cause varying degrees of liver damage. Therefore, an understanding of herbal hepatotoxicity and rational use of $\mathrm{CHM}$ is of great importance. The aims of this review were to discuss clinical cases of liver injury caused by $\mathrm{CHM}$, describe the diagnosis, clinical patterns and mechanisms of hepatotoxicity, explore the common causes of adverse reactions, detail current shortcomings and make suggestions for future prospects.

\section{Clinical overview}

\section{Reported cases}

A comprehensive analysis of Chinese academic journals indicated that of the 9355 total cases of drug-induced liver injury (DILI) reported between 2001 and 2010, approximately $20 \%$ of these (1979 cases) were associated with herbs. ${ }^{3}$ Another report by Jie et al. examining 337 cases of DILI from 2009 to 2012 found that $44.2 \%$ of the cases of liver injury were caused by CHM. ${ }^{4}$ Although the incidence rates of herbal druginduced liver injury (HILI) are different among the various regions of China, the percent of $\mathrm{CHM}$-induced liver injury from literature published in 2013 ranged from 26.4 to $49 \%$. These data indicate that CHM-induced liver injury in China is an issue that cannot be ignored. Although there are fewer relevant reviews and case reports of liver injury caused by herbal medicine from other countries, the annual average number of herbal hepatotoxicity-related publications in PubMed has increased from 4.2 in 1990-1999 to 9.9 in 2000-2009. There are currently 185 articles, and nearly 60 kinds of herbs implicated in possible liver damage. ${ }^{5}$ Based on available data of DILI cohorts from the US and Europe, herbal products may be a cause of hepatotoxicity in $2-11 \%$ of patients with DILI, and in $5-10 \%$ of patients with drug-induced acute liver failure. ${ }^{6}$

\section{Clinical characteristics}

In general, compared with Western medicine, liver damage caused by $\mathrm{CHM}$ develops slowly with clinical symptoms appearing within one week to one month. ${ }^{7}$ The clinical manifestations can be classified as acute hepatitis, sub-acute hepatitis, and cirrhosis. Clinical symptoms such as fatigue 
$(67.3 \%)$, jaundice $(60.3 \%)$, anorexia $(58.0 \%)$, nausea $(35.9 \%)$, and fever $(19.3 \%)$ are more common, but signs such as rash, pruritus and clay-colored stools have also been reported. ${ }^{8}$ CHM-induced liver injury can also develop into liver failure. A study of 418 patients with DILI by Teng et al. reported 81 cases of liver failure, $19.4 \%$ of which had clinical manifestations similar to those caused by viral or alcoholic hepatitis. ${ }^{8}$ Investigations regarding HILI also suggest that women are more susceptible, ${ }^{4,9}$ especially for those 60-65 years of age. ${ }^{10}$ The susceptibility may be due to age- and sexrelated differences in hepatic microsomal enzyme activity.

\section{Diagnosis}

Because of the variety of clinical features and time of onset, there is no gold standard for diagnosing DILI or CHM-induced liver injury. The Council for International Organizations of Medical Sciences (CIOMS) scale is the most commonly used method for assessing causality in cases of DILI ${ }^{11}$ and HILI, ${ }^{12}$ and is currently considered as the best causality assessment method. For physicians treating a patient with suspected DILI or HILI, the CIOMS scale can be used to prospectively collect all necessary parameters without requiring an expert panel. ${ }^{13}$ Compared to other assessment methods, including the Maria-Victorino scale, ${ }^{14}$ Aithal and Day method, ${ }^{15}$ Aithal, Rawlins, and Day method, ${ }^{16}$ and Takikawa, Takamori, and Kumagi scale, ${ }^{17}$ the CIOMS scale offers excellent sensitivity, specificity and predictive validity (based on cases with positive re-exposures). ${ }^{18}$ Due to the complexity of Chinese medicinal ingredients, it is difficult to determine the reference data on herbal hepatotoxicity, and thus misdiagnoses and missed diagnoses are more likely to occur. Therefore, the clinical diagnosis of liver injury caused by herbal medicine focuses more on medical and medication histories. Physicians should first make a comprehensive comparison of clinical manifestations and related enzymology indices before, during and after treatment, followed by a diagnosis of exclusion. The important conditions to exclude are hepatitis A, B, and C, alcoholic liver disease, biliary obstruction, and liver injury due to ischemia or other medications. ${ }^{19}$ Although causality assessment methods, such as the CIOMS scale, are better approaches for reaching the correct diagnosis of DILI and HILI than liver histology, ${ }^{20}$ liver biopsy should still be considered as a final diagnostic approach in rare instances of diagnostic uncertainty.

\section{CHM that have been linked to hepatotoxicity}

The following CHMs reportedly can cause liver injury: Dioscorea bulbifera, Gynura segetum, Fructus xanthii, Polygonum multiflorum, Tripterygium wilfordii Hook F, Folium artemisiae argyi, Occidentalis, Atractylodes lancea, trichosanthin, Loranthaceae, Cyrtomium fortunei, cattail pollen, ephedra, Bupleurum, Folium senna, centipede, Albizia julibrissin, clove, Fructus toosendan, Brucea javanica, Ilex pubescens, castor beans, Veratrum nigrum, Salvia miltiorrhiza, Papaver somniferum, Rhizoma Pinelliae, Alisma orientalis, rhubarb, Polygonum cuspidatum, groundsel, Menispermaceae, Dysphania ambrosioides, nutmeg, Phytolacca acinosa, antipyretic Dichroa, chaulmoogra, cinnabar, Rafetus swinhoei, pangolin, Scutellaria, valerian, aconite, and ginkgo. ${ }^{21}$ The known hepatotoxic components in CHM can be divided into five categories according to their chemical structures: alkaloids, terpenoids, glycosides, toxic proteins, and tannins. ${ }^{22}$ Some of the most common CHMs that cause hepatotoxicity are shown in Table 1.

\section{The pathogenesis of liver injury caused by $\mathrm{CHM}$}

Although little is known about the pathogenesis of $\mathrm{CHM}$ induced liver injury, there are various theories on the pathogenesis of DILI, including the participation of "toxic metabolites" that either elicit an immune response or directly affect cellular biochemical processes or functions. ${ }^{23}$

\section{Direct toxicity}

Drugs are generally safe when given at recommended doses. However, the intrinsic toxicity of a drug at higher doses is a major cause of acute liver failure and transplantation. ${ }^{24}$ DILI is initiated by direct hepatotoxic effects of a drug or its reactive metabolites. ${ }^{25}$ Hepatocyte death, which can be either apoptotic or necrotic, ${ }^{26}$ is the primary outcome, although bile duct epithelium or sinusoidal endothelial cells may also be involved in liver injury. ${ }^{27}$ Dioscorea bulbifera $L$. presents a classical example of direct liver injury. ${ }^{28}$ It has been shown that diosbulbin from Dioscorea bulbifera $L$. causes excessive exhaustion of liver glutathione amounts, and reduces levels of normal liver antioxidants, resulting in oxidative stress injury. ${ }^{29}$ The reactive oxygen species produced during oxidative stress can modify and inactivate lipids, proteins, DNA, and RNA, and thus lead to apoptotic or necrotic cell death. ${ }^{30}$

\section{Idiosyncratic reactions}

The majority of adverse liver reactions are idiosyncratic, occurring in most instances 5-90 days after the causative medication was last taken. Such idiosyncratic reactions can be divided into metabolic and immune idiosyncrasy. Metabolic idiosyncrasy is often associated with genetic polymorphisms of cytochrome P450. Electrophilic and free radical metabolites are produced by the activation of cytochrome enzymes, and levels of intermediate metabolites, protein-DNA complexes and other metabolites are increased, which can form toxic metabolites that cause liver damage. ${ }^{31}$ In this mechanism, the alkaloids mentioned above produce toxic metabolites resulting in liver toxicity. Pyrrolizidine alkaloids in Sedum aizoon and Senecio are transformed by cytochrome P450 into unstable toxic metabolites, which damage sinusoidal endothelial cells and cause blood disorders. ${ }^{32}$

Immune-mediated idiosyncratic liver injury can be seen as an immune response. Drugs or their metabolites act as haptens and are processed by immunocompetent cells and converted to new antigens. These antigens then stimulate the body to produce antibodies that can induce an immune response and cause liver damage. It has been shown that Tripterygium wilfordii can cause unpredictable liver injury, which has a certain relationship with the activation of Kupffer cells in the liver and the release of large amounts of tumor necrosis factor and carbon monoxide. ${ }^{33}$ Because liver injuries caused by idiosyncratic reactions frequently have a long incubation period and are unpredictable, timely detection of liver damage and treatment is difficult, which results in adverse prognoses. 
Ma X. et al: Chinese herbal medicine-induced liver injury

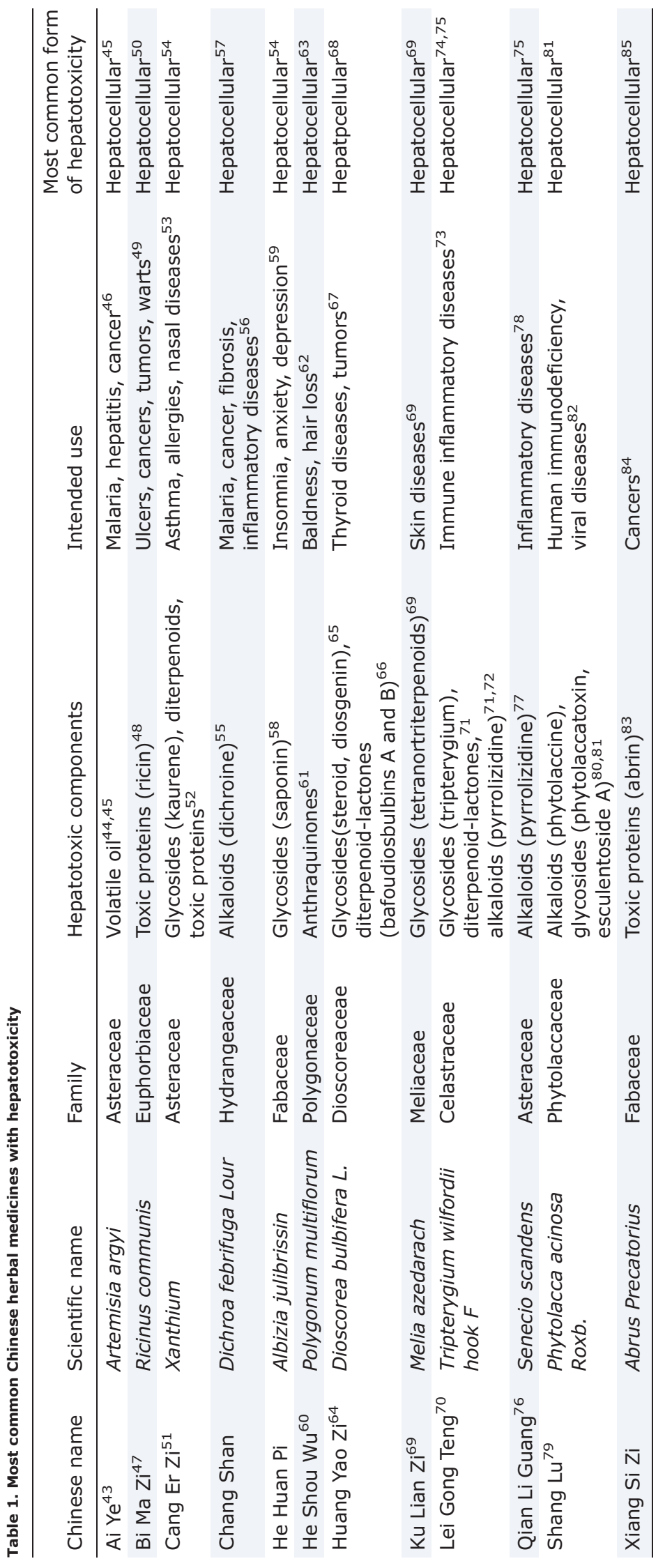


Ma X. et al: Chinese herbal medicine-induced liver injury

Factors contributing to $\mathrm{CHM}$-induced liver injury

\section{Misunderstanding of $\mathrm{CHM}$}

The most frequent factor involved in $\mathrm{CHM}$-induced liver injury is a misunderstanding of $\mathrm{CHM}$. The public generally regards CHM as "natural" and "safe". However, the earliest Chinese medical classic "The Inner Canon of Huangdi" classifies CHMs as having high, moderate, or low toxicity, or as being nontoxic. Furthermore, recent toxicologic studies found that some chemical compositions of the herbs classified as nontoxic can cause liver toxicity. ${ }^{34}$

\section{Misuse, abuse and overdose}

Liver injury caused by the misuse or abuse of $\mathrm{CHM}$ and some folk remedies is common. Clinical data showed that of the 427 cases of liver injury at the Beijing Ditan Hospital that were caused by $\mathrm{CHM}$, two cases were due to accidental ingestion, and in 62 cases, the medications were taken without a prescription. ${ }^{35}$ In another 25 cases of HILI caused by Fallopia multiflora, excessive dosage was the suspected cause in ten patients. ${ }^{36}$

\section{Poor quality}

The quality of the drug is one of the most important factors affecting CHM safety. CHMs are likely contaminated during the process of growth, collection, storage, transportation and manufacture. ${ }^{37}$ Uncontrolled processing can also result in the production of toxic components. For example, cocklebur is usually stir-fried before use in the clinic. Both reduced frying time and uneven heating can lead to toxicity by incomplete degeneration of the toxic protein. ${ }^{38}$

\section{Improper compatibility of medicines}

Compatibility means that two or more kinds of herbs can be used in any combination to achieve the most effective and safe treatment through the interactions among them. On the other hand, incompatibility can not only reduce the effectiveness, but also increase toxicity. The compatibility can significantly reduce the extent of liver cell damage via the antagonism of Angelica against Dioscorea bulbifera $L$. on mRNA expression levels of CYP2E1 and CYP1A2. ${ }^{39}$

These situations can be improved by increasing public awareness, precise diagnosis and treatment, and strict quality supervision. However, the adverse reactions due to differences in sensitivity, reactivity, and tolerance of individuals still may not effectively be controlled.

\section{Future improvements and prospects}

The growing number of clinical case reports and laboratory research results clearly shows that some Chinese herbs have a certain liver toxicity. Studies on the diagnosis, treatment and mechanism have not kept pace. Not only doctors and researchers, but also the media and pharmaceutical companies, should share the responsibility to avoid CHM-induced liver injury and to use herbs safely. These issues deserve attention in future studies.

\section{Limitations of diagnosis}

Due to the lack of specific diagnostic criteria, there exists a certain degree of difficulty in diagnosing liver injury caused by $\mathrm{CHM}$, resulting in misdiagnoses or missed diagnoses, as well as delays in treatment. ${ }^{40}$ On the other hand, because of the limitation in the diagnosis, in some clinical reports, a past medical history of CHM is sometimes the only clue to the diagnosis. ${ }^{41}$ The European Medicines Agency assessed 31 spontaneous cases of assumed HILI by black cohosh reported from countries within the European Union. Following the application of the CIOMS scale, only one case of suspected HILI from black cohosh remained, equivalent to $3 \%$ of the reported cases. ${ }^{42}$ Therefore, the establishment of diagnostic criteria is a top priority, and for doctors, the knowledge and understanding of the pathogenesis, clinical manifestations and treatment will also assist in detecting liver injury and administering timely and effective treatment.

\section{Development of toxicology studies}

Toxicology studies on CHM are still limited, and further research is needed. The focus of future studies should be on determination of toxic doses, and limiting of doses, providing important reference for rational herbal medicine use.

\section{Dissemination of the standardized application of CHM}

The public awareness of CHM also needs to be improved. This is the responsibility of the public media and the government. Public media needs to educate the public on the rational use of medicinal herbs, and national regulatory authorities should monitor the quality of the herbs, strictly regulate the doses of medicine, and make regulations to forbid non-prescription remedies.

\section{Conclusions}

With the popularity of traditional Chinese medicine in the global market, adverse reactions caused by CHM are increasing. CHM-induced liver injury presents many clinical patterns and clinical manifestations. There is still no gold standard for diagnostic criteria. Advances in the understanding of the frequency, the clinical manifestations and the pathogenesis can improve the accuracy of diagnosis and improve the safety of $\mathrm{CHM}$.

\section{Conflict of interest}

None

\section{Author contributions}

Writing the article (XM), polishing the manuscript (YYH), polishing and organizing the manuscript, revising the manuscript and replying the reviewer's advice (JHP).

\section{References}

[1] Tachjian A, Maria V, Jahangir A. Use Of Herbal Products And Potentia Interactions In Patients With Cardiovascular Diseases. J Am Coll Cardiol 2010;55:515-525. doi: 10.1016/j.jacc.2009.07.074. 
[2] Die junge Generation wendet sich den Naturheilmitteln zu. Allensbacher Berichte, Nr. 17, 1989.

[3] Yao F, Wang YY. Statistic analysis of the 9355 patients with drug induced liver injury. Anhui Medical and Pharmaceutical Journal 2011;15:1312-1314.

[4] Sun J, Yu F, Wang J. Clinical Characteristics and Drug Analysis in 337 Cases of Drug induced Liver Injury. Pharmaceutical and Clinical Research 2013;4: 383-387. (Article in Chinese)

[5] Teschke R, Wolff A, Frenzel C, Schulze J, Eickhoff A. Herbal hepatotoxicity: a tabular compilation of reported cases. Liver Int 2012;32:1543-1556. doi: 10.1111/j.1478-3231.2012.02864.x.

[6] Bunchorntavakul C, Reddy K. Review article: herbal and dietary supplement hepatotoxicity. Aliment Pharmacol Ther 2013;37:3-17. doi: 10.1111/ apt.12109.

[7] Shao Y, Li DS. Clinical Analysis of Patients with medicine Induced and Traditional Medicine-Induced Liver Injury. Journal of Clinical Internal Medicine 2010;27:827-828. (Article in Chinese)

[8] Teng Guangju, Sun Ying, Chang Binxia. The clinical features and prognosis analysis of 418 patients with drug-induced liver injury. Chinese Hepatology 2013;18:11-14. (Article in Chinese)

[9] Kessler RC, Davis RB, Foster DF, Van Rompay MI, Walters EE, Wilkey SA, et al. Long-term trends in the use of complementary and alternative medical therapies in the United States. Annals Of Internal Medicine 2001;135:262268.

[10] Lucena MI, Andrade RJ, Kaplowitz N, García-Cortes M, Fernández MC, Romero-Gomez $\mathrm{M}$, et al. Phenotypic characterization of idiosyncratic drug induced liver injury: the influence of age and sex. Hepatology 2009;49: 2001-2009. doi: 10.1002/hep.22895.

[11] Tajiri K, Shimizu Y. Practical guideline for diagnosis and early management of drug-induced liver injury. World J Gastroenterol 2008;14:6774-6785.

[12] Teschke R, Schulze J, Schwarzenboeck A, Eickhoff A, Frenzel C. Herbal hepatotoxicity: suspected cases assessed for alternative causes. Eur J Gastroenterol Hepatol 2013;25:1093-1098

[13] Teschke R, Eickhoff A, Schulze J. Drug and herb induced liver injury in clinical and translational hepatology: Causality assessment methods, quo vadis? J Clin Translat Hepatol 2013;1:59-74. doi: 10.14218/JCTH.2013.D002X

[14] Maria VA, Victorino RM. Development and validation of a clinical scale for the diagnosis of drug-induced hepatitis. Hepatology 1997;26:664-669. doi: 10.1002/hep.510260319.

[15] Aithal PG, Day CP. The natural history of histologically proved drug induced liver disease. Gut 1999;44:731-735. doi: 10.1136/gut.44.5.731.

[16] Aithal GP, Rawlins MD, Day CP. Accuracy of hepatic adverse drug reaction reporting in one English health region. BMJ 1999;319:1541. doi: 10.1136/ bmj.319.7224.1541.

[17] Takikawa H, Takamori $\mathrm{Y}$, Kumagi T, Onji M, Watanabe M, Shibuya A, et al. Assessment of 287 Japanese cases of drug induced liver injury by the diagnostic scale of the International Consensus Meeting. Hepatol Res 2003; 27:192-195. doi: 10.1016/S1386-6346(03)00232-8.

[18] Teschke R, Wolff A, Frenzel C, Schwarzenboeck A, Schulze J, Eickhoff A. Drug and herb induced liver injury: Council for International Organizations of Medical Sciences scale for causality asse ssment. World J Hepatol 2014;6: 17-32. Doi: 10.4254/wjh.v6.i1.17.

[19] Agarwal VK, McHutchison JG, Hoofnagle JH, Drug-Induced Liver Injury Network (DILIN). Imp ortant elements for the diagnosis of drug-induced liver injury. Clin Gastroenterol Hepatol 2010;8:463-470. doi: 10.1016/ j.cgh.2010.02.008.

[20] Kleiner DE, Chalasani NP, Lee WM, Fontana RJ, Bonkovsky HL, Watkins PB, et al. Hepatic histological findings in suspected drug-induced liver injury: Systematic evaluation and clinical associations. Hepatology 2014;59:661670. doi: 10.1002/hep.26709.

[21] Xu LM, Lin QX. Hepatic toxicity of Chinese herbal medicine. Chinese Journal of Hepatology. 2007;15:534-535. (Article in Chinese)

[22] Hu YY, Huang F. Chinese herb and drug-induced liver injury. Chinese Journal of Hepatology 2012;2:173-175. (Article in Chinese)

[23] Kaplowitz N. Biochemical and cellular mechanisms of toxic liver injury. Semin Liver Dis 2002;22:137-144. doi: 10.1055/s-2002-30100

[24] Grattagliano I, Bonfrate L, Diogo CV, Wang HH, Wang DQ, Portincasa P. Biochemical mechanisms in drug-induced liver injury:Certainties and doubts. World J Gastroenterol 2009,39:4865-4876.

[25] Holt MP, Ju C. Mechanisms of drug-induced liver injury. AAPS ] 2006;8: E48E54. doi: 10.1208/aapsj080106.

[26] Malhi H, Gores GJ, Lemasters J]. Apoptosis and necrosis inthe liver: a tale of two deaths? Hepatology 2006;43:S31-S44. doi: 10.1002/hep.21062.

[27] Tarantino G, Di Minno MN, Capone D. Drug-induced liver injury:Is it somehow foreseeable? World J Gastroenterol 2009;23:2817-2833.

[28] Liu NN, Xu L, Shi L, Li Y, Lin LF. Advances in toxicology of saponins-contained traditional chinese medicine. Central South Pharmacy 2010;8:916-919. (Article in Chinese)

[29] Wang J, Ji L, Liu H, Wang Z. Study of the hepatotoxicity induced by Dioscorea bulbifera L. rhizome in mice. Bioscience trends 2010;4:79-85.
[30] Pacifici RE, Davies KJ. Protein, lipid and DNA repair systems in oxidative stress: the free-radical theory of aging revisited. Gerontology 1991;37:166180. doi: $10.1159 / 000213257$.

[31] Li Chen. Research progress of Chinese herbal medicine induced liver damage. Journal of Clinical Hepatology 2013;16:278-281. (Article in Chinese)

[32] Cai HD, Sun FX. Pyrrolizidine alkaloids-containing plants and hepatic venoocclusive disease. Adverse drug reactions Journal 2007;9:229. (Article in Chinese)

[33] Huang JF, Jiang ZZ, Wang T, Yao JC, Zhang LY. Overview of Research on Druginduced Liver Injury. Progress in Pharmaceutical Sciences 2008;32:357362. (Article in Chinese)

[34] Xia JQ, Xi ZH. Prevention of traditional Chinese medicine-induced liver damage during the treatment of liver disease. Chinese Journal Of General Practice 2010;08:1287-1288. (Article in Chinese)

[35] Chen YF, Cai HD. Investigation of liver damage associate with traditional Chinese medicine. Adverse Drug Reactions Journal 1999;1:27-32. (Article in Chinese)

[36] Jung KA, Min HJ, Yoo SS, Kim HJ, Choi SN, Ha CY, et al. Drug-Induced Liver Injury: Twenty Five Cases of Acute Hepatitis Following Ingestion of Polygonum multiflorum Thunb. Gut And Liver 2011;5:493-499. doi: 10.5009/gnl.2011.5.4.493.

[37] Zhang L, Yan J, Liu X, Ye Z, Yang X, Meyboom R, et al. Pharmacovigilance practice and risk control of Traditional Chinese Medicine drugs in China: Current status and futur e perspective. J Ethnopharmacol 2012;140:519525. doi: 10.1016/j.jep.2012.01.058

[38] Jin CS, Wu DL, Zhang JS. Effects of different processing methods on constituents and pharmacological action of fructus xanthii. Journal of anhui traditional chinese medical college 2000;19:54-56. Doi: 10.3969/ j.issn.1000-2219.2013.00.000

[39] Liu DZ, Zhao XG. The study developments on etiological factor pathomechanism and TCM treatment of hepatic injury. Forumon Traditional Chinese Medicine 2006;21:53-55. (Article in Chinese)

[40] Teschke R, Glass X, Schulze J, Eickhoff A. Suspected Greater Celandine Hepatotoxicity: Liver-Specific Causality Evaluation Of Published Case Reports From Europe. Eur J Gastroenterol Hepatol 2012;24:270-280. doi: 10.1097/MEG.0b013e32834f993f

[41] Teschke R, Frenzel C, Glass X, Schulze J, Eickhoff A. Herbal hepatotoxicity: A critical review. Br J Clin Pharmacol 2013;75:630-636. Doi: $10.1111 /$ j.1365-2125.2012.04395.x

[42] http://www.ema.europa.eu/docs/en_GB/document_library/Herbal__HMPC_assessment_re port/2010/02/WC500074167.pdf, accessed May 2007.

[43] Wang BS. Absinthism. Chinese Journal of Internal Medicine 1955;3:941943.

[44] Lao A, Fujimoto $Y$, Tatsuno T. Studies on the constituents of Artemisia argi Levi et Vant. Chem Pharm Bull 1984;32:723-727. doi: 10.1248/cpb.32.723.

[45] Judzentiene A, Budiene J, Butkiene R, Kupcinskiene E, Laffont-Schwob I, Masotti V. Caryophyllene oxide-rich essential oils of Lithuanian Artemisia campestris ssp. campestris and their toxicity. Nat Prod Commun 2010;5: 1981-1984.

[46] Willco, M. Artemisia species: From traditional medicines to modern antimalarial and back again. J Altern Complement Med 2009;15:101-109. doi: $10.1089 / \mathrm{acm} .2008 .0327$

[47] Wang JX. Clinical analysis of 56 cases of acute poisoning induced by castor bean. Chinese Community Doctors. 2013;09:205-206. (Article in Chinese)

[48] Wedin GP, Neal JS, Everson GW, Krenzelok EP. Castor bean poisoning Am J Emerg Med. 1986;4:259-261.

[49] Scarpa A, Guerci A. Various uses of the castor oil plant (Ricinus communis L.). A review. J Ethnopharmacol 1982;5:117-137. doi: 10.1016/03788741(82)90038-1.

[50] Nie K, Li YX, Zhao XF, Wang S. Summary of the Liver Toxicity of Traditional Chinese Medicine. Journal Of Practical traditional Chinese Internal medicine 2009;12:112-114.

[51] Wu XZ. 14 cases of myocardial damage and liver damage caused by Cang Er Zi. Yi Xue Li Lun Yu Shi Jian. 1996;9:312-312. (Article in Chinese)

[52] MacLeod JK, Moeller PD, Franke FP. Two toxic kaurene glycosides from the burrs of Xanthium pungens. J Nat Prod 1990;53:451-455. doi: 10.1021/ np50068a025.

[53] But $P$, Chang $C$. Chinese herbal medicine in the treatment of asthma and allergies. Clin Rev Allergy Immunol 1996;14:253-269.

[54] Obatomi DK, Bach PH Biochemistry and toxicology of the diterpenoid glycoside atractyloside. Food Chem Toxicol 1998;36:335-346. doi: 10.1016/S0278-6915(98)00002-7.

[55] Li CC, Chen Z. Observation on Hydrangeas role in fighting malaria and its preliminary pharmacological. Fu Jian Yi Xue Yuan Xue Bao. 1959;1:93-97. (Article in Chinese)

[56] Keller TL, Zocco D, Sundrud MS, Hendrick M, Edenius M, Yum J, et al. Halofuginone and other febrifugine derivatives inhibit prolyl-tRNA synthetase. Nat Chem Biol 2012;8:311-317. doi: 10.1038/nchembio.790 
[57] Arseculeratne SN, Gunatilaka AA, Panabokke RG. Studies on medicinal plants of Sri Lanka: occurrence of pyrrolizidine alkaloids and hepatotoxic properties in some traditional medicinal herbs. J Ethnopharmacol 1981;4:159-177. doi: 10.1016/0378-8741(81)90033-7.

[58] Ikeda T, Fujiwara S, Araki K, Kinjo ], Nohara T, Miyoshi T. Cytotoxic glycosides from Albizia julibrissin. J Nat Prod 1997;60:102-107. doi: 10.1021/ np960556t.

[59] Yeskaliyeva B, Mesaik M A, Abbaskhan A, Kulsoom A, Burasheva GSh, Abilov $\mathrm{ZhA}$, et al. Bioactive flavonoids and saponins from Climacoptera obtusifolia. Phytochemistry 2006;67:2392-2397. doi: 10.1016/j.phytochem. 2006.07.003.

[60] Zhang L, Yang X, Sun Z, Qu Y. Retrospective study of adverse events of Polygonum multiflorum and risks control. Zhongguo Zhong Yao Za Zhi 2009; 34:1724-1729. (Abstract in English, article in Chinese)

[61] Sun XH, Sun YW, Li H, Sun W. Influence of main component of Heshouwu such as emodin, rhein and toluylene glycoside on hepatic cells and hepatoma carcinoma cell. Modern Journal Of Integrated Traditional Chinese And Western Medicine 2010;11:1315-1317, 1319. (Article in Chinese)

[62] Park HJ, Zhang N, Park DK. Topical application of Polygonum multiflorum extract induces hair growth of resting hair follicles through upregulating Sh and $\beta$-catenin expression in C57BL/6 mice. J Ethnopharmacol 2011;135: 369-375. doi: 10.1016/j.jep.2011.03.028.

[63] Banarova A, Koller T, Payer J. Toxic hepatitis induced by Polygonum multiflorum. Vnitr Lek 2012;58:958-962.

[64] Huang ZF, Hua BC, Chen XF, Shi DH, Cheng XL, Wang YH, et al. Analysis of Liver Injury in 78 Cases Caused by Rhizoma Dioscoreae Bulbiferae and Related Preparation. Chinese Journal of Experimental Traditional Medical Formulae 2013;23:295-297.

[65] Komoif T. Glycosides from Dioscorea btflbifera. Toxicon 1997;35:15311535. doi: 10.1016/S0041-0101(97)00032-9

[66] Teponno R B, Tapondjou A L, Gatsing D, Djoukeng JD, Abou-Mansour E, Tabacchi $\mathrm{R}$, et al. Bafoudiosbulbins $\mathrm{A}$, and $\mathrm{B}$, two anti-salmonellal clerodane diterpenoids from Dioscorea bulbifera L. var sativa. Phytochemistry 2006; 67:1957-1963. doi: 10.1016/j.phytochem.2006.06.019.

[67] Marc S, Anne-Claire MO, Marie-Aleth LD. The Dioscorea genus: a review of bioactive steroid saponins. J Nat Med 2007;61:91-101.

[68] Wang J, Ji L, Liu H, Wang Z. Study of the hepatotoxicity induced by Dioscorea bulbifera L. rhizome in mice. Biosci Trends 2010;4:79-85.

[69] Phua DH, Tsai WJ, Ger J, Deng JF, Yang CC. Human Melia azedarach poisoning. Clin Toxicol 2008;46:1067-1070. doi: 10.1080/15563650802310929.

[70] Liang WK, Kuang J]. Liver damage related to triptolide and its preparations: domestic literatures review and analysis. Chinese Journal of Drug Application And Monitoring 2011;03:169-172. (Article in Chinese)

[71] Zhou Y, Zhang L, Liu W. Protective effect of total glucosides of paeony against acute hepatic injury induced by tripterygium glycosides tablet in mice.
Tianjin Journal of Traditional Chinese Medicine 2007;1:28. (Article in Chinese)

[72] Zhang Y,Jiang Z,Xue M,Zhang S, Wang Y, Zhang L. Toxicogenomic analysis of the gene expression changes in rat liver after a 28-day oral Tripterygium wilfordii multiglycoside exposure. J Ethnopharmacol 2012;141:170-177. doi: $10.1016 / j$.jep.2012.02.015.

[73] Tao X, Lipsky PE. The Chinese anti-inflammatory and immunosuppressive herbal remedy Tripterygium wilfordii Hook F. Rheum Dis Clin North Am 2000; 26:29-50.

[74] Peng B, Miao MS, Wang YL. Initial discussion of mice acute hepatic injury caused by Tripterygium glycosides. Zhongguo Zhong Yao Za Zhi 2003;28: 1067-1070. (Article in Chinese)

[75] Yeong ML, Clark SP, Waring JM, Wilson RD, Wakefield SJ. The effects of comfrey derived pyrrolizidine alkaloids on rat liver. Pathology 1991;23:3538. doi: 10.3109/00313029109061438.

[76] Zuckerman M, Steenkamp V, StewartMJ. Hepatic veno-occlusive disease as a result of a traditional remedy: confirmation of toxic pyrrolizidine alkaloids as the cause, using an in vitro technique. J Clin Pathol 2002;55:676-679. doi: 10.1136/jcp.55.9.676.

[77] WHO. Environmental Health Criteria 80, pyrrolizidine alkaloid, 1988.

[78] Tian XY, Wang YH, Yang QY, Liu X, Fang WS, Yu SS. Jacaranone glycosides from Senecio scandens. J Asian Nat Prod Res 2006;8:125-132. doi: 10.1080/10286020500530912.

[79] Guo BK, Zhang FQ, Zhang L, Liu Y. Clinical analysis on 10 cases of acute pokeberry root poisoning. Chinese Journal Of Industrial Medicine 2005;01: 32-33. (Article in Chinese)

[80] Lampe, K F., McCann, M A. AMA Handbook of poisonous and injurious plants. Chicago: American Medical Association, 1985.

[81] Zhou Q,Yao GT, Jin RM, Xie JJ. Hepatotoxicity induced by esculentoside A. Chinese Traditional Patent Medicine 2014;36:14-18.

[82] Zarling JM,Moran PA,Haffar O, Sias J, Richman DD, Spina CA, et al. Inhibition of HIV replication by pokeweed antiviral protein targeted to $C D+4$ cells by monoclonal antibodies. Nature 1990;347:92-95. doi: 10.1038/347092a0

[83] Silva AL, Goto LS, Dinarte AR, Hansen D, Moreira RA, Beltramini LM, et al. Pulchellin, a highly toxic type 2 ribosome-inactivating protein from Abrus pulchellus. Cloning heterologous expression of A-chain and structural studies. FEBS J 2005;272:1201-1210. doi: 10.1111/j.1742-4658.2005. 04545.x.

[84] Wawrzynczak E J, Cumber A J, Henry R V, May J, Newell DR, Parnell GD, et al. Pharmacokinetics in the rat of a panel of immunotoxins made with abrin $A$ chain, ricin A chain, gelonin, and momordin. Cancer res 1990;50:7519 7526.

[85] Bhasker AS, Sant B, Yadav P, Agrawal M, Lakshmana Rao PV. Plant toxin abrin induced oxidative stress mediated neurodegenerative changes in mice. Neurotoxicology 2014;44C:194-203. doi: 10.1016/j.neuro.2014.06.015. 